\title{
NOTCH3 Gene Mutation
}

National Cancer Institute

\section{Source}

National Cancer Institute. NOTCH3 Gene Mutation. NCI Thesaurus. Code C158057.

A change in the nucleotide sequence of the NOTCH3 gene. 